\title{
Going virtual with practical chemistry amidst the COVID-19 pandemic lockdown: significance, constraints and implications for future
}

\author{
Lahiru A. Wijenayaka and Sithy S. Iqbal \\ The Open University of Sri Lanka, Nawala, Sri Lanka
}

\begin{abstract}
Purpose - Although technology is a defining characteristic of distance education, assessment of the applicability of such resources in knowledge dissemination is greatly warranted to ensure effectivity. Hence, the purpose of this study was to assess the viability of a novel tool in teaching practical chemistry online.

Design/methodology/approach - Here, a resource named "virtual chemistry lab space" (VCLS), which allowed the learners to virtually engage in practical activities, was administered among learners enrolled in a practical chemistry course at the Open University of Sri Lanka and feedback was collected to ascertain the learner perception on the resource.

Findings - In total, $76 \%$ of respondents indicated familiarity with the VCLS, while $59 \%$ indicated that they were interested in engaging in activities provided through this resource during the pandemic lockdown. Also, $70 \%$ indicated that the VCLS was helpful to understand the course content during the pandemic period, while $82 \%$ indicated that they are likely to use it in the future.

Research limitations/implications - The prevalent problems related to using the VCLS were lack of Internet access, physical interactions and time. However, the overall opinion on the VCLS was notably positive, while a majority indicated that flexibility to the learners, access to learning resources and use of technology in education will improve due to the use of this novel tool.

Originality/value - Online course delivery has been greatly restricted to areas of education where distant delivery could be easily adopted while it is seldom found in areas such as practical chemistry. Hence, the study indicates novelty and notable originality within the ODL system.
\end{abstract}

Keywords Chemistry, COVID-19, Online, Practical, Technology, Virtual

Paper type Research paper

\section{Introduction}

Technology plays a pivotal role in distance education (Bates and Bates, 2005; Casey, 2008; Clark, 2000), while the use of technology is considered not as an option, but a defining characteristic of the teaching-learning relationship in distance education (Moore, 2013; Willis, 1993). However, often it is observed that the incorporation of technology in various forms such

(C) Lahiru A. Wijenayaka and Sithy S. Iqbal. Published in Asian Association of Open Universities Journal. Published by Emerald Publishing Limited. This article is published under the Creative Commons Attribution (CCBY 4.0) licence. Anyone may reproduce, distribute, translate and create derivative works of this article (for both commercial and non-commercial purposes), subject to full attribution to the original publication and authors. The full terms of this licence may be seen at http://creativecommons. org/licences/by/4.0/legalcode

The authors wish to acknowledge the developers of the OER used in this study, Prof. Gayathri Jayathileka, Acting Director of the Center for Educational Technology and Media, OUSL for the guidance provided in conducting the study, and Mr Anurakavan Sripathmanathan, Ms Vidumini Samarasiri and Ms Sandamini Senaratne for the assistance provided in data acquisition and statistical analysis.

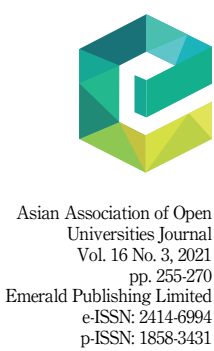


AAOUJ 16,3

as means of delivery, assessment or learner support in education indicates notable limitations. Inherent constraints that include lack of infrastructure, lack of technical competence or even the lack of motivation, etc. have been previously reported to be responsible for such limitations (Galusha, 1998; Tabata and Johnsrud, 2008). Hence, it is important to recognize any potential limitations and take precautionary action to minimize the same if technology is to allow the effective dissemination of knowledge (Chen, 2009; Christensen, 2002). Nevertheless, during the recent halt in academic activities that took place globally as a result of the COVID-19 pandemic, academics were warranted to relook at how technology can be used at all levels of education, thus allowing education to be continued amidst the social lockdown (Ali, 2020; Chick et al., 2020; Daniel, 2020; Ferdig et al., 2020; Goh and Sandars, 2020). Hence, under the prevailing social circumstances, it has become an immediate necessity to understand the efficacy as well as learner perception of including technology in facilitating education, specifically for areas where online delivery is seldom practiced.

\section{Literature reviews}

A laboratory-based practical component that provides hands-on exposure to chemistryrelated experimentation is considered essential in chemistry curricula at the undergraduate level. Typically, skills in practical chemistry are grasped easier by conducting them physically in an actual laboratory setting. Hence, technological tools are used seldom for content delivery in practical chemistry. Nevertheless, with the advancement of technology, there are many recently developed software, animations and virtual and augmented reality simulations that allow users to receive a virtual chemistry laboratory experience without any physical presence. In a previous study, Georgiou et al. have demonstrated the successful use of virtual reality simulations for distance education in chemistry, claiming that such technology plays a major role in education, as they provide realistic models with which learners can interact to acquire real-world experiences, while providing a safe environment in which learners can repeat processes without any risk, enabling learners to perceive concepts and theories easier (Georgiou et al., 2007). Notably, Erwin Boschmann had claimed similar traits in another study conducted via the use of web-based television sessions for chemistryrelated content delivery (Boschmann, 2003), while other contemporary reports add credit to the above claims (Dalgarno et al., 2009, 2012).

It is no doubt that the ongoing COVID-19 pandemic has transformed the global educational system resulting in a rapid transition from face-to-face classroom-based education to online content delivery (Tigaa and Sonawane, 2020). Consequently, there had been many recent reports where technology was successfully adopted in content delivery at the university level during the recent halt that took place due to the COVID-19 pandemic (Ali, 2020; Basilaia et al., 2020; Chick et al., 2020; Code et al., 2020; Daniel, 2020; Ferdig et al., 2020; Goh and Sandars, 2020). However, although the general perception of online education is that it would provide academics with the flexibility to continue teaching regardless of social circumstances, many institutional, technological, as well as perceptional factors may commonly hinder the successful utility of online content delivery methodologies in many instances. Hence, this sudden upsurge of the use of technology in education was still greatly restricted to the areas of education where distant delivery was easily adopted while it was seldom found in areas such as practical chemistry (Campbell et al., 2020; Qiang et al., 2020; Tran et al., 2020; Valle-Suárez et al., 2020).

The inherent limitations in assessing practical chemistry via virtual tools and the difficulty to gauge the ensuing understanding of learners via online assessment tools had been prominently identified as the limiting factor in this regard (Fergus et al., 2020; Huang, 2020; Rodríguez-Rodríguez et al., 2020; Soares et al., 2020; Tran et al., 2020). In their recent study, Tran et al. have identified (1) experimental implementation; (2) assessments and postlab activities; (3) technological inequalities; and (4) synchronization of student attendance as 
the major challenges which academics would face in transitioning practical chemistry into an online mode (Tran et al., 2020). However, under the "new normal" social conditions and the ensuing social distancing guidelines adopted due to the ongoing pandemic, conventional laboratory-based sessions are unlikely to take place during the foreseeable future. Hence, it is inevitable that the academic and higher educational institutions would have to adopt technology-based tools in delivering practical chemistry content if education is to progress amidst the pandemic.

\section{Research overview}

CYU3302-Basic Practical Chemistry is a three-credit course offered for Level 3 (i.e. freshman or first-year) learners at the Open University of Sri Lanka (OUSL). The course is aimed at providing a thorough understanding of basic concepts related to practical chemistry, while developing fundamental experimentation skills, and is hence facilitated mainly via academic activities that are conducted in person. It is typical that learners may enroll in the course with minimal or no prior laboratory experience, and thus, the in-person laboratory sessions are considered as a salient mandatory activity for learners enrolled in the course.

However, due to the recent cessation of academic activities that took place globally due to the COVID-19 pandemic, all in-person activities were suspended due to the stringent health regulations. Thus, unlike the theory-based courses where course delivery continued amidst the pandemic via online teaching approaches, minimal alternatives could be adopted to continue the delivery of courses that included practical components, given the inherent difficulty of effectively delivering such content via online teaching methodologies. Alternatively, here a resource composed of virtual chemistry simulations and animations was created using open educational resources (OER) to facilitate learning during the pandemic lockdown, and it was administered among learners enrolled in the course CYU3302 via the university learner management system (LMS).

Notably, in addition to the pros and cons of adopting technology in education identified in previous studies, there are likely many other "local" factors, typically those specific to the cohort of students enrolled at a particular academic institution, that may hinder the adoption of technological tools in education. As such, it is inevitable that a detailed analysis of the strengths, weaknesses, opportunities, as well as threats in adopting online content delivery in education, needs to be carefully evaluated at a level that is focused specifically on the cohort of learners concerned. Hence, this study was designed to evaluate if the "virtual chemistry lab space" (VCLS) serves as an alternative and effective platform for supplementary teaching of practical chemistry to OUSL learners. Accordingly, the objective of this study was to use the feedback collected from learners regarding their background and inclination to use technology in education, use of the VCLS during the period of pandemic lockdown and accessibility and perception on the VCLS to eventually understand the effectivity of using the VCLS for content delivery in practical chemistry in distance education.

\footnotetext{
Methodology

A resource named as "virtual chemistry lab space" (VCLS) was developed using OER that have been specifically designed to provide a virtual experience in preparing for, performing and analyzing chemical laboratory activities via computer-based simulations. The VCLS was hosted in the university LMS, OUSL Elearn, and it was administered among learners enrolled in the course CYU3302. Due to the pandemic lockdown that was in effect during the period from March to June 2020, all course-related communication and delivery took place online through Elearn. Hence, the information regarding VCLS was shared among the enrolled learners via a message sent through Elearn informing them to use the resource as needed while the pandemic lockdown was in effect. Typically, the learners enrolled in this course are
}

Practical
chemistry
amidst
COVID-19

257 


\section{AAOUJ 16,3}

\section{8}

Figure 1.

Schematic flow of the experimental methodology adopted in the study. Here, an alternative voluntary pathway was provided to the learners by allowing them to engage in the VCLS before participating in the in-person laboratory-based sessions

Figure 2.

Distribution of learners based on (A) gender, (B) age group and (C) employment status

expected to directly participate in the laboratory-based practical activities, where they engage in hands-on practical chemistry. Nevertheless, the resources provided in the VCLS allowed the learners to virtually engage in activities, akin to what they would perform in the laboratory, prior to participating in the laboratory-based practical activities. Notably, the use of the VCLS was completely voluntary. Hence, although the use of the VCLS was recommended, it was not made compulsory to the learners by any means due to the various restrictions that the learners may face in adopting novel technologies. Therefore, the VCLS provided a voluntary alternative pathway for learners to engage in course activities as summarized schematically in Figure 1.

Once academic activities resumed after the pandemic lockdown that followed the first wave of the COVID-19 pandemic in Sri Lanka, the learners were brought back into the university to participate in the regular in-person laboratory-based practical sessions, while it was anticipated that the learners who were familiar with the theory and techniques of the experiments involved with the session by use of the VCLS would indicate better proficiency in performing the laboratory activities. To validate this hypothesis, a survey was conducted by administering a feedback questionnaire specifically designed to anonymously evaluate (1) background and inclination to use technology in education; (2) use of the VCLS during the period of pandemic lockdown; and (3) accessibility and perception on the VCLS of the learners. Eventually, the feedback collected from 208 learners enrolled in the course after they completed the in-person practical session was analyzed. Statistical analysis was conducted using the $R$ statistical package and the Pearson's chi-squared test was performed to evaluate the association between variables wherever appropriate.

\section{Results and discussion}

\section{Demographic distribution of learners}

Distribution of the 208 learners who completed the feedback questionnaire, based on gender, age group and employment status is presented in Figure 2 panels $(A),(B)$ and $(C)$ respectively. As can be seen in panel (A), the gender of learners included in the study showed the typical composition seen under similar contemporary academic settings with the majority being

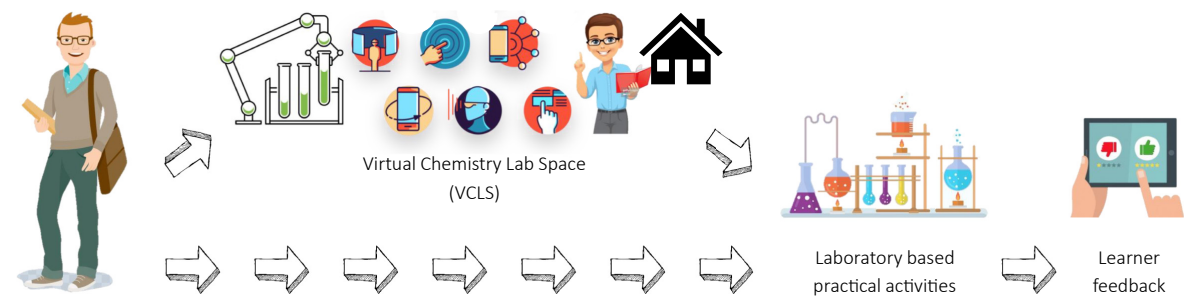

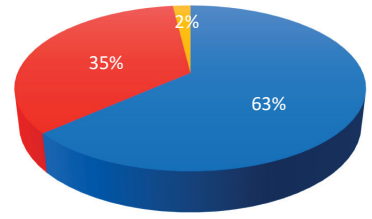

(A)

=Female $=$ Male $=$ Unspecified

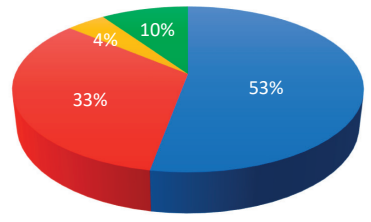

(B)

$\because<25=25-30 \quad \approx>30 \quad=$ Unspecified

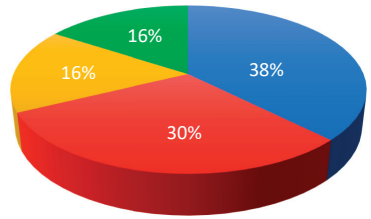

(C)

- Full-time employed 1 Part-time employed = Full-time student $\quad$ Unspecified 
female learners. As for age, shown in panel (B), it is visible that the majority $(53 \%)$ of the learners were less than 25 years of age, while $4 \%$ were above 30 years. It should be noted that although not large, the latter fraction may include adult learners from diverse backgrounds with minimal or no previous exposure to the use of technology in education. Nevertheless, a salient feature of open and distance learning (ODL) is the provision of opportunity for adult learners to engage in education (Devisakti, 2016; Dzakiria, 2012) and hence the inclusion of the opinion of the above fraction of learners would be imperative in the study of concern. As for the employment status as shown in panel (C), a significant proportion $(68 \%)$ of learners were employed, while only $16 \%$ were full-time learners. This, in turn, would be a matter of concern given the time requirement associated with using the VCLS, specifically as the use of the resource was regarded as completely voluntary. Overall, it is apparent that the learners considered in the study include individuals from all different demographic backgrounds concerned, hence indicating that the ensuing conclusions would not be biased by any specific subset of learners.

\section{Inclination to use technology in education}

Distribution of learners based on their familiarity with the VCLS, how they found out about the VCLS, and the technology-related activities used in support of their academic work at the OUSL are presented in Figure 3 panels (A), $(B)$ and (C), respectively. As can be seen in panel (A), a significant majority $(73 \%)$ indicated that they were familiar with the VCLS; a clear indication of the inclination of the learners toward using the VCLS. At the same time, $7 \%$ of the learners indicated that they were completely unaware of the VCLS, while it should be noted that including the opinions of such individuals in the survey would decrease the potential of any subjective bias being in place. Noting the differences in how the learners identified their awareness of the VCLS in the above analysis, it would be important to further understand any potential reasons for the differences in the awareness levels among the learners. Hence, responses were collected to evaluate as to how the individual learners found out about the VCLS, while the findings are summarized in Figure 3 (B). According to this, only $41 \%$ of the learners had seen the message sent by the senior coordinator (course instructor) regarding the VCLS, while $22 \%$ of the learners found out about it through colleagues: a likely indication of collaborative learning. Another $30 \%$ of learners found out about it when they logged into Elearn, while 6\% indicated that they did not know anything about the VCLS; likely the same subsection of learners that indicated that they were completely unaware of the VCLS in the previous analysis (Figure $3(\mathrm{~A})$ ).

To further understand the inclination of the learners to use technology in education, feedback was sought as to which activities the learners have used (or currently use) in support of their academic work at the OUSL. The findings here are summarized in Figure 3 (C), and as can be seen, majority of learners were aware of browsing the Internet for subjectrelated material, using software and mobile applications (apps), and using audiovisual resources as support for academic activities. It is notable that given the availability and use of technology of present times, such activities might be considered mundane. However, looking at the feedback provided on using interactive simulations as that conducted through the VCLS, or more extraordinary activities such as developing their own programs or coding, it is clear that the majority of the learners were unaware or "not sure" of the usage of such resources in academic activities. Importantly, this indicates the novelty of adopting the VCLS as a tool in an educational setting, specifically within the cohort of learners who participated in this study. Nevertheless, it is notable that $29 \%$ of the learners have indicated that they had prior knowledge on developing their own programs/coding for academic activities, indicating that the technical competence required for using tools such as the VCLS is indeed present among a significant proportion of learners.

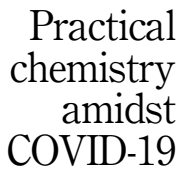

259 


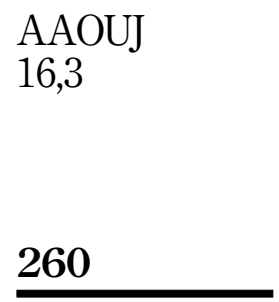

Figure 3.

Distribution of learners based on (A) familiarity with the VCLS, (B) how they found out about the VCLS and (C) technology-related activities they have used in support of their academic work at the OUSL

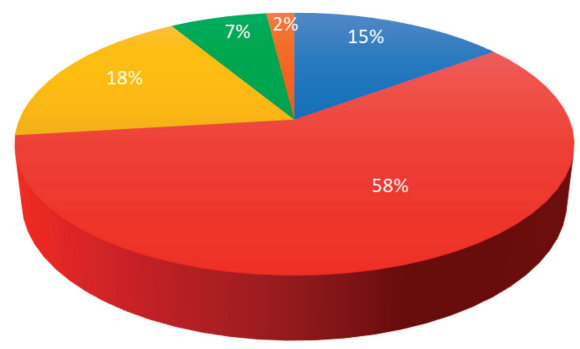

- Very familiar

a Somewhat familiar

wave heard about it, but not familiar with it

$\square$ Do not know anything about it

No response

(A)

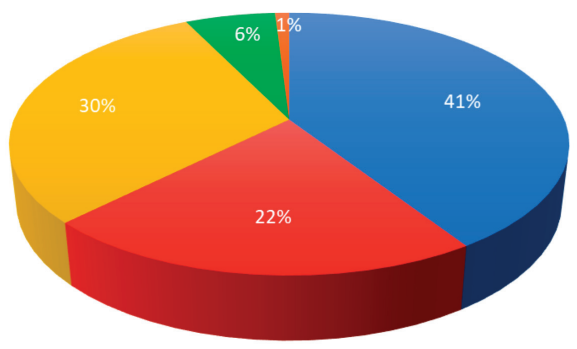

॥ Saw the message sent by the course coordinator

- Heard about it from collegues

« Saw it when logged into Elearn

- Do not know anything about it

- No response

(B)

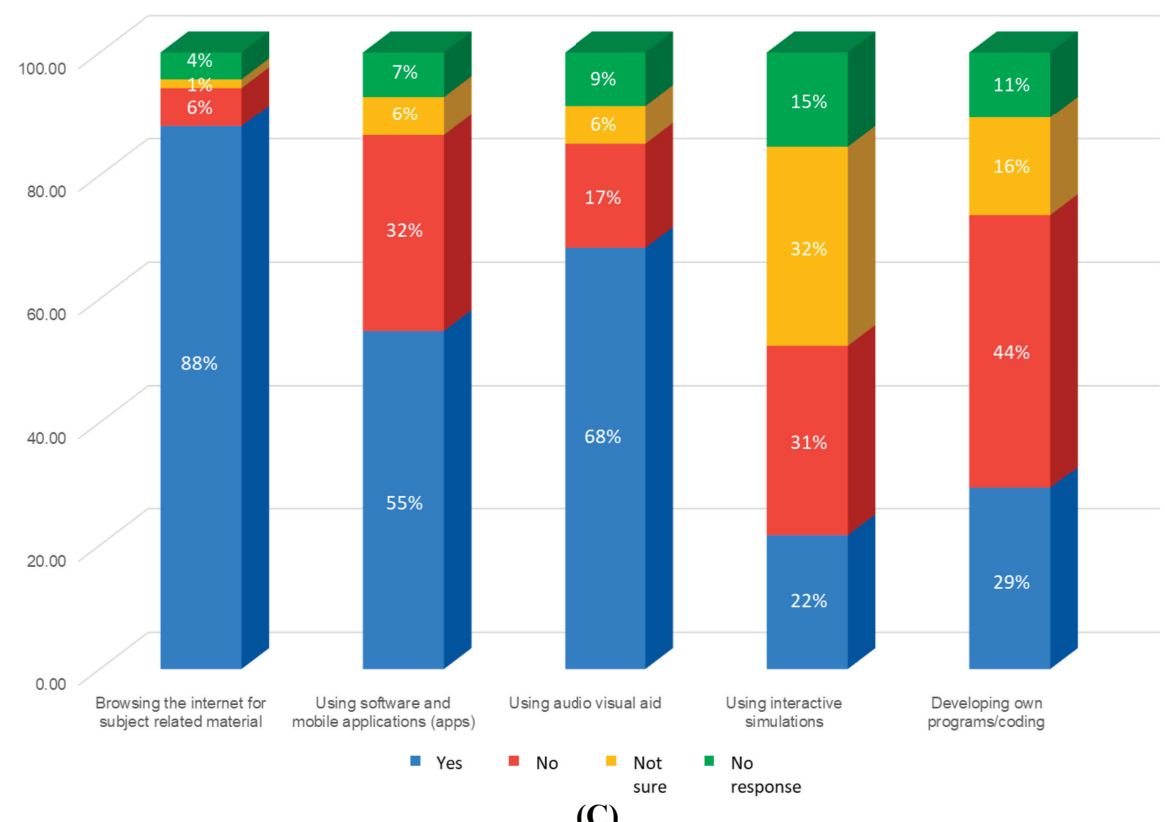

(C)

Use of the VCLS during the period of pandemic lockdown

Feedback received in terms of the use of the VCLS by learners during the COVID-19 pandemic lockdown that took place in Sri Lanka from March to June 2020 is summarized in Figure 4. As seen here in panel (A), although a significant proportion $(69 \%)$ of learners indicated that they had used the VCLS during the pandemic lockdown period, $30 \%$ indicated that they did not use it at all. This, however, was anticipated as the use of the VCLS was voluntary, as opposed to what has been previously observed with compulsory or semi-compulsory activities used as learner support (Tait, 2002).

Further to use, feedback was also sought to assess the interest of the learners for engaging in activities provided in the VCLS as summarized in Figure 4 (B). As can be seen, majority of 
learners $(59 \%)$ indicated that they were interested in using the VCLS, while nearly half of them indicated that they were "very interested" in using the resource. Another $14 \%$ indicated that they would have used the VCLS if they had known about it during the pandemic lockdown, while $11 \%$ indicated that they were not interested in using the VCLS but used it as there was free time. Collectively, this could be regarded as an overall positive response to the use of technology to facilitate learning either directly or indirectly during periods of controlled social interactions. It further emphasizes the importance of effective communication regarding such activities to the learners, given that a notable fraction of learners were, unfortunately, unaware of the VCLS during the pandemic lockdown.

Although notable concern could be placed on the $15 \%$ of learners who did not use the VCLS, while they knew about the resource, it should be noted that such behavior could have been minimized or perhaps obviated altogether by making the VCLS compulsory for the learners, in contrast to the voluntary practice adopted herein. Hence, the feedback collected was analyzed further to understand the statistical association between the demographic background and the familiarity, use and interest on the VCLS of the learners, to identify any potential limitations in the use of the VCLS based on the demographic background of the learners.

\section{Familiarity, use and interest in the VCLS and the demographic background of learners}

The feedback questionnaire used in this study was designed to gather information regarding the opinion of learners on the VCLS at three distinct levels of association. First, feedback on the "interest" of learners to engage in the activities provided in the VCLS was collected. The interest was anticipated to be influenced by the learner motivation, while likely being independent of their demographic distribution. Second, information regarding the "use" of the VCLS during the pandemic period was gathered. The "use" in contrast to "interest" was expected to be associated with the demography of the learners, especially as the "age group" is likely to have an association with the inclination toward technology, while "employment status" will dictate how much time one may have to use this supplementary (non-compulsory) resource. Third, the "familiarity" of the VCLS was assessed, which is likely to result via the "interest" and the eventual "use" of the VCLS. Hence, yet again "familiarity" was expected to be dependent on the demographic factors of the learners.

Accordingly, to determine the association between the familiarity of the VCLS, use during the pandemic and the interest in using the resource (presented in Figure 3(A), 4(A), and 4(B),

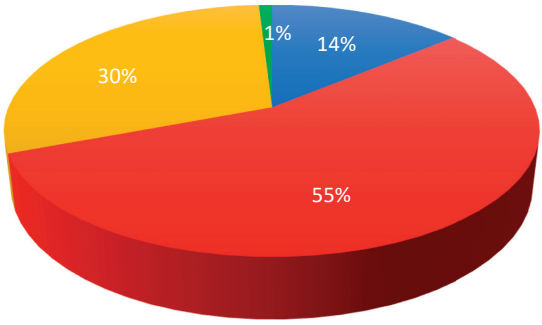

(A)

$$
\begin{aligned}
& =\text { Used it a lot } \\
& =\text { Used it a little } \\
& =\text { Didn't use it at all } \\
& =\text { No response }
\end{aligned}
$$

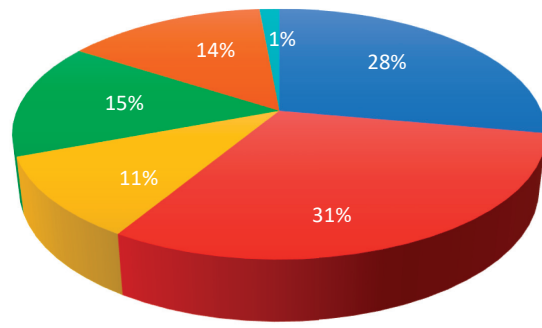

(B)

- Very interested

@ Somewhat interested

Not interested, Just used it as there was free time

- Knew about it during that time, but didn't use it

aidn't know about it during that time. Would have used it if I knew

No response
Practical
chemistry
amidst
COVID-19

261

\section{(1)}


AAOUJ 16,3

\section{2}

Table 1.

The $p$ values obtained for the Pearson's chisquared test for the association of

"familiarity," "use" and "interest" of learners on the VCLS with their demographic background respectively) and the demographic variables of learners, the Pearson's chi-squared test was performed. Typically, the Pearson's chi-squared test evaluates how likely it is that any observed difference between the sets of categorical data resulted by chance. Here, the value of $p$ will be less than 0.05 if the two variables are independent, whereas if $p$ is greater than 0.05 , the two variables are considered non-independent.

The $p$ values obtained here are summarized in Table 1 . As can be seen, the "interest" in using the VCLS does not show any association with the gender or age group of learners, indicating that such technological learner support tools are accepted alike across different gender and age groups, especially during times where conventional delivery is disrupted. However, the interest of learners in using the VCLS indicates association with the employment status: a likely result of the time required for engaging in the VCLS, while employed learners are likely to find less time to engage in supplementary learner support resources of this nature. On the contrary, use and the familiarity of the VLCS on the other hand are seen to be associated with each demographic variable considered here. Hence, overall, these findings suggest that the VCLS or any other resource of this nature would allow equal access to learners of all backgrounds during a lockdown period, indicating its potential use as an effective alternative teaching methodology. However, it should be noted that the demographic distribution of learners needs to be carefully considered if optimal use of technological resources is to be ensured.

\section{Learner rating of VCLS components}

The VCLS was composed of three main sections, namely, (1) PhET interactive simulations; (2) basic laboratory operations; and (3) virtual laboratory simulations, specifically designed to provide an understanding of the activities typically undertaken by the learners within the lab. More precisely, PhET interactive simulations were a collection of OER virtual simulations identified as relevant to the course CYU3302. These simulations had been developed by the University of Colorado Boulder, USA (CC-BY), using Java, Flash or HTML5, and they could be run online or downloaded to a computer. The second component, basic laboratory operations were a collection of virtual resources developed by the American Association of Chemistry Teachers and LibreTexts (CC BY-NC-SA 3.0), focusing on basic laboratory operations such as measuring volumes, preparing solutions and observing chemical reactions, etc. The third component was virtual laboratory simulations, developed by ChemCollective (a project in the National Science Digital Library, USA) (CC BY-NC ND). This section focused on the more intricate course-related activities that are typically undertaken by the learners in the laboratory such as solution preparation and quantitative chemical analysis.

Here, the learners were requested to rate the above components of the VCLS in terms of their use and the help provided by each component in understanding the course content in CYU3302 as summarized in Figure 5 panels $(\mathrm{A})$ and $(\mathrm{B})$, respectively. As can be seen in panel (A), majority of learners $(>50 \%)$ indicated that they have used the components on basic laboratory operations and virtual laboratory simulations at least once, while a lesser fraction $(36 \%)$ indicated they use $\mathrm{PhET}$ interactive simulations. A similar trend was observed in terms of the help provided by each component in understanding the course content as can be seen in panel

\begin{tabular}{lccr}
\hline Demographic variable & Familiarity & $\begin{array}{c}\text { Attribute } \\
\text { Use }\end{array}$ & Interest \\
\hline Gender & 0.7588 & 0.5330 & 0.0038 \\
Age group & 0.7544 & 0.4847 & 0.0270 \\
Employment status & 0.8217 & 0.4778 & 0.5864
\end{tabular}


(B), where the majority of learners $(>50 \%)$ indicated that the components on basic laboratory operations and virtual laboratory simulations were "helpful" in understanding the course content, while a lesser proportion $(40 \%)$ indicated a similar response for $\mathrm{PhET}$ interactive simulations. Notably, sizeable proportions (30\% and $22 \%$, respectively) of learners indicated that using the components on basic laboratory operations and virtual laboratory simulations was "very helpful" in understanding the course content, indicating the effectivity of the use of technology to facilitate distance and online learning during the pandemic lockdown. This fact is further evidenced by the negligible proportions of learners who indicated that each component was "not helpful" in understanding the course content, indicating the overall positive attitude of the learners in adapting to novel teaching methodologies.

\section{Opinion on using the VCLS to teach practical chemistry}

To further understand the perception of the learners on the VCLS, opinion of learners on using the VCLS to facilitate learning during the pandemic lockdown and the likeliness of using the VCLS in future, perhaps during another pandemic lockdown, were collected as summarized in Figure 6 panels (A) and (B), respectively. As clearly seen, a significant majority (70\%) indicated that the VCLS was helpful in understanding the course content during the pandemic period, while $51 \%$ indicated that they are "very likely" to use it in the future, while another $31 \%$

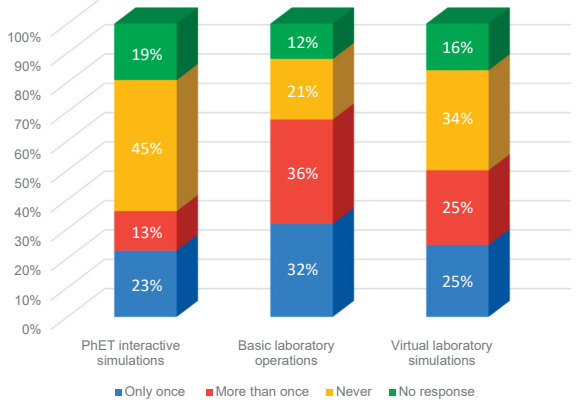

(A)

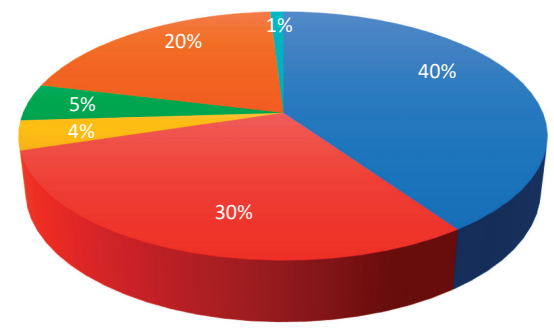

(A)

- It was very helpful in understanding the course content

- It was somewhat helpful in understanding the course content

w It was not helpful in understanding the course content

Not sure

- Can't say anything. Haven't used it yet

No response

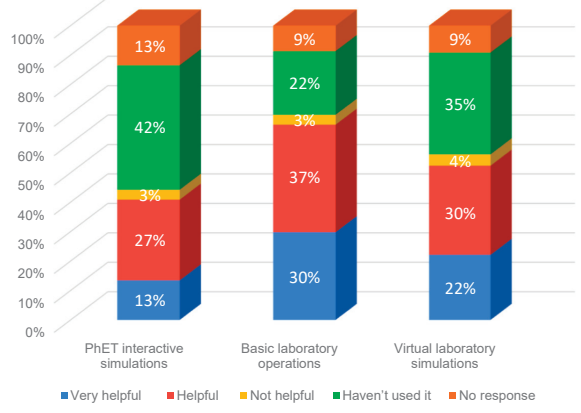

(B)

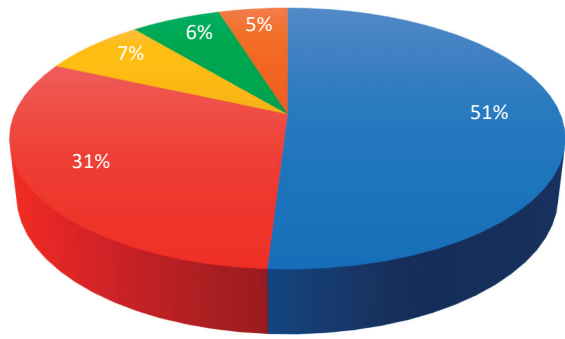

(B)

चery likely

- Somewhat likely

in am not sure

Unlikely. I will probably have other important things to attend

- No response
Practical
chemistry
amidst
COVID-19

263
Figure 5.

Rating of the components of the VCLS by learners based on (A) their use and (B) help provided in understanding the course content by each component included in the VCLS
Figure 6.

(A) Opinion of learners on using the VCLS to facilitate learning during the pandemic lockdown and (B) likeliness of using the VCLS in future 
AAOUJ 16,3

\section{4}

indicated that as "likely", given that there would be time away from other professional and academic responsibilities. Of note, only negligible potions $(<10 \%)$ of learners had a negative opinion on each case as visible in Figure $6(\mathrm{~A})$ and $(\mathrm{B})$. Hence, this result perfectly reinstates the overall positive attitude of the learners in adapting to novel teaching methodologies. In reality, the social distancing practices adopted with the intervention of the COVID-19 pandemic are still in place in many parts of the world continuing to interrupt the routine in-person educational activities to be in place, and hence this result suggests that such virtual activities are perfectly viable to continue education with minimal or hopefully no interruptions under the "new normal" social circumstances, even for practical-based course for which such virtual activities are seldom practiced for content delivery.

\section{Accessibility, limitations and the future potential of the VCLS}

Further, to understand any potential limitations in adopting the VCLS, feedback was collected to assess what devices were used by learners to access the VCLS, while the findings here are summarized in Figure 7 (A). It is apparent that a significant majority (69\%) indicated that they have used a smartphone to access the resource, while relatively lesser proportions had access to a laptop, desktop or tablet computer. Apparently, only $4 \%$ of the learners indicated that they did not have access to any of the above devices (note that percentages above were determined based on the total number of respondents (208), as there was a substantial portion of learners who accessed the VCLS via multiple devices). Hence, collectively, the data collected on device accessibility suggest that (1) the use of technologyrelated teaching tools is a viable alternative given that the vast majority of learners had access to devices to be used for such purposes, (2) while emphasizing the need to develop applications or programs that are compatible with mobile devices, given that large numbers would prefer to use the resources on such platforms. Typically, many virtual resources used to date may require the assistance of software or hardware requirements that are typically associated with computers, but not smartphones. Hence, the above results suggest the importance to select resources that would have minimal system requirements while they could be run on mobile platforms such that many who would prefer to use mobile devices for educational purposes would not be at stake.

Many previous reports suggest Internet-based teaching has notable potential for the effective dissemination of knowledge (Carswell et al., 2000; Eddy and Spaulding, 1996; Guohong et al., 2012). However, it is important to assess the limitations specific to the VCLS if it is to be administered among learners in an effective manner. Hence, feedback was collected to assess the problems related to using the VCLS as per the experience of the learners in using the resource. This information is summarized in Figure 7 (B) and it is apparent that the lack of time, interest, Internet access, knowledge on technology to use such resources and guidance

Figure 7.

(A) Devices used by learners to access the VCLS, (B) problems related to using the VCLS and (C) opinion on replacing part of the laboratory work associated with the practical sessions of the course by online activities using the VCLS in future

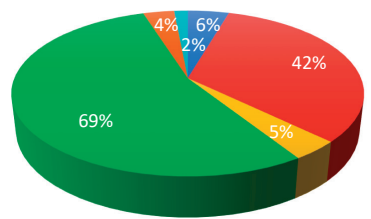

(A)

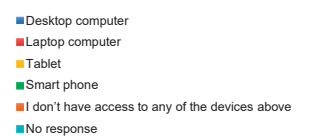

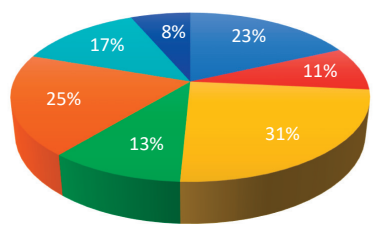

(B)

- Lack of time

Lack of interest

II Lack of internet access

- Lack of knowledge on technology to use these resources

- Difference between working in a real lab and virtual simulations

- Lack of guidance through staff-student interactions when using the virtual lab

- No response

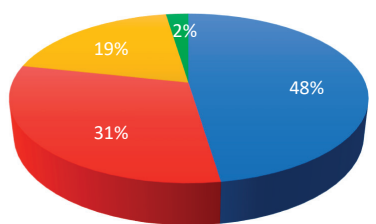

(C)

- Good. I think that's a good idea = No. I don't think that will be good =1 am not sure - No response 
through staff-student interactions that typically occurs during in-person sessions, as well as the difference between working in a real lab and virtual simulations were identified as potential problems associated with using the VCLS. However, among these, lack of Internet access $(31 \%)$, the difference between working in a real lab and virtual simulations $(25 \%)$, and lack of time $(23 \%)$ were identified as the most prominent drawbacks (Note that percentages above were determined based on the total number of respondents (208), as there was a substantial portion of learners who identified multiple of the above as problems associated with the VCLS). Similar observations have been made in a study conducted by Galusha and Jill, where the loss of motivation due to lack of face-to-face contact with teachers and peers, and lack of faculty support was found to diminish the efficacy of distance learning (Galusha, 1998). Hence, the findings here collectively emphasize the need to (1) carefully manage the resources selected for such purposes based on the intensity of Internet usage; (2) need to accommodate supplementary in-person sessions to provide the physical interactions that lack in such online delivery methods; and (3) design online activities such that they would not require a large amount of time, thus being a burden, specifically in the case of full-time or parttime employed learners.

The ultimate objective of developing technological tools such as the VCLS is to evaluate their potential to be adopted in educations, perhaps even after the social distancing-based limitations to conventional content delivery are lifted. It is notable that many reports have had a close look at the pedagogical implications of such action, while some reports claim the effective application during the recent pandemic (Al-Fahad, 2009; Basilaia et al., 2020; Bates and Bates, 2005; Brown and Liedholm, 2002; Code et al., 2020; Goh and Sandars, 2020; Ng, 2007). Here, the opinion of the learners on replacing part of the laboratory work associated with the practical sessions of the course with online activities using the VCLS in future was sought to attain similar insights specific to the cohort of individuals concerned herein. The results are summarized in Figure 7 (C), which indicates that a significant proportion (48\%) indicated that this would be a good idea, while another sizeable proportion (31\%) indicated that they did not think that will be good, indicating an ambivalence among the learners: a likely result of the prevalent problems associated with using the VCLS.

\section{Overall perception of learners on the VCLS}

The learner perception on the effect on different attributes in education if part of the laboratory work associated with the course CYU3302 was replaced by online activities using the VCLS in future was sought. The findings here are summarized in Figure 8 (A) and as clearly seen significant proportions of learners indicated that flexibility to the learners $(65 \%)$, access to learning resources $(73 \%)$ and use of technology in education $(77 \%)$ will improve via the use of the VCLS, while only a negligible proportion $(<8 \%)$ indicated pessimism on each aspect. Particularly, in their recent study, Rodriguez et al. describes the adaptation of an online teaching model for selected chemistry courses. Here, although students preferred to carry out a face-to-face teaching and learning process, they found certain advantages in the online teaching modality, such as the saving of time and flexibility as is observed herein (Valle-Suárez et al., 2020). Notably, relatively lesser proportions of learners indicated that use of the VCLS would improve the exposure to laboratory techniques $(42 \%)$ and staff-student interactions $(27 \%)$, while larger proportions $(>20 \%)$ indicated pessimism in this regard, whereas another significant proportion were "not sure" of their opinion. Such results, however, could be anticipated given the conventional delivery methods typically adopted in practical related courses and the inherent lack of hands-on exposure and physical interactions that may result from online delivery methods.

Additionally, some of the notable comments made by learners regarding the VCLS include "if the actual experiments that are conducted in the lab could be included in the VCLS, it would be very helpful as we are familiar with the instructions and techniques", "please put more

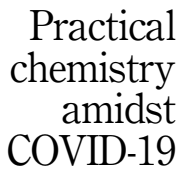

265 


\section{AAOUJ 16,3}

\section{6}

Figure 8.

Learner perception on (A) the effect on different attributes in education if part of the laboratory work associated with the course was replaced by online activities using the VCLS in future, (B) overall opinion on the VCLS and (C) the likeliness to recommend their colleagues to use the VCLS as an academic support tool

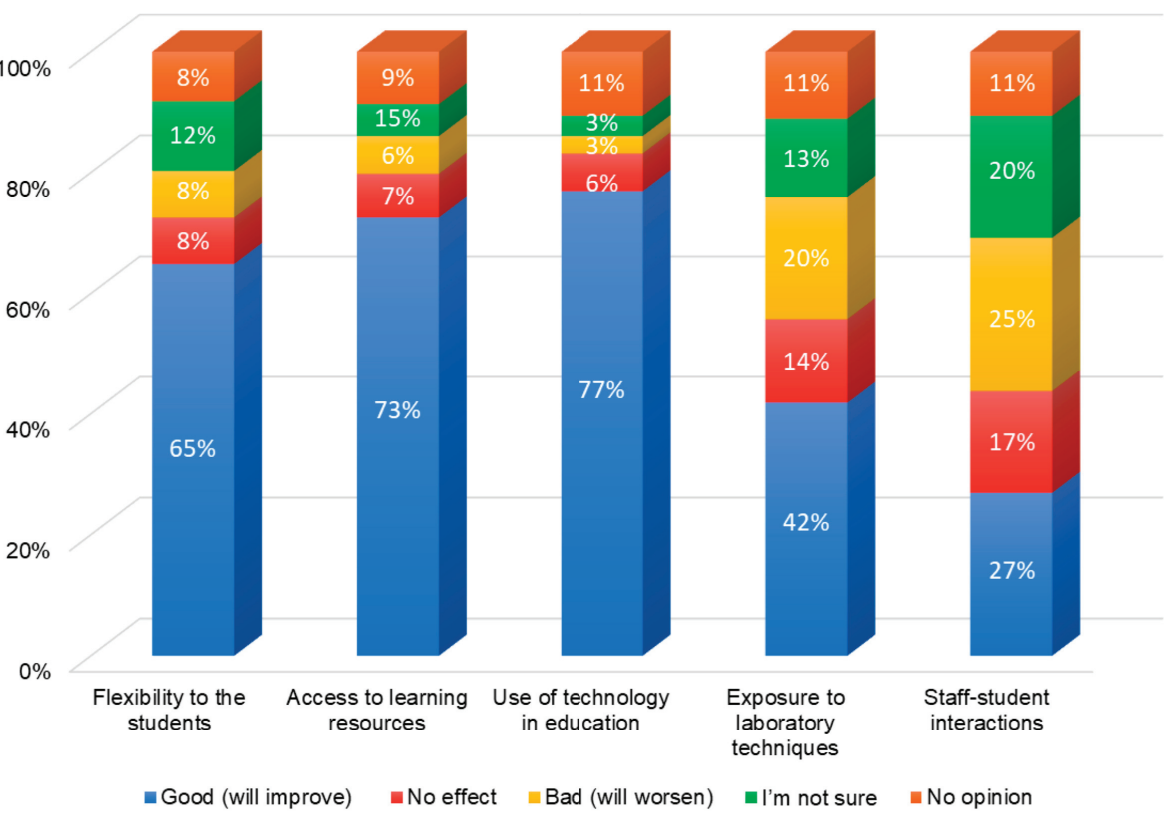

(A)

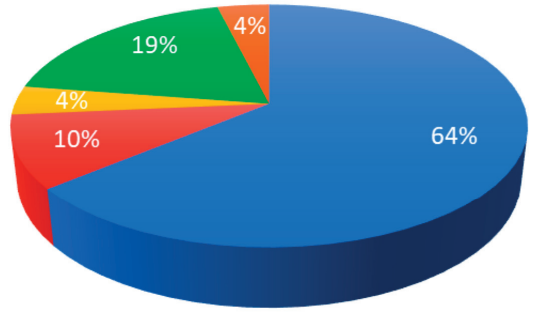

- It was interesting and helpful for the course

- It was interesting, but not helpful for the course

- It was neither interesting nor helpful for the course

not sure as I have not used it yet

No response

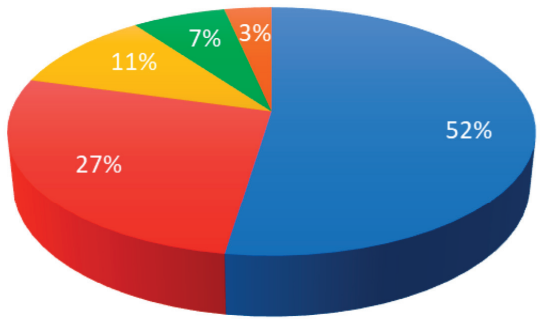

- Very likely

- Somewhat likely

I I am not sure

I I will not recommend using it

no response

(C)

related videos and model answers," and "a proper guideline would be good". These comments collectively highlight the importance of carefully selecting and if possible, amending the activities to match those conducted during the in-person activities, while providing clear instructions and supplementary guidance for the students to engage as well as self-assess the activities conducted via the VCLS. Additionally, comments such as "it should be improved in a way with some quizzes after each laboratory session" indicate that the utility of the resource could be further enhanced by incorporating quizzes. In fact, such action would assist the learners to gauge their understanding resulted via the use of the virtual activities, while at the same time providing a tool to the instructors to monitor the use by each individual learner: both 
of which are effective attributes of an effective teaching methodology. Comments such as "notifications should be given as a reminder since not everyone is always online and will be a working people" further highlight the need to examine better ways to communicate with learners, while emphasizing the need to provide direct or indirect motivation to the learners for using supplementary learner support resources of this nature as was previously discussed previously in accordance to the findings of this study (vide supra).

Nevertheless, the overall opinion of the learners on the VCLS was greatly positive as summarized in Figure 8 (B). The majority of the learners $(64 \%)$ have indicated that the VCLS was interesting and helpful for the course, while only a negligible proportion (4\%) indicated that the VCLS was neither interesting nor helpful for the course. Further, a considerable fraction of learners $(10 \%)$ indicated that it was interesting, although not helpful for the course. This, however, could be addressed by the careful design and selection of resources to be used for the VCLS as highlighted by some of the learner comments as previously mentioned. Additionally, it resonates an emphasis to develop tailor-made virtual resources to capture the elements outlined in the corresponding course content, as opposed to adopting any system that has been designed and developed for general use. Hence, developing virtual resources in house or at least in direct connection to the course syllabus may be a more viable approach in broadening the applicability of virtual teaching tools, although unfortunately, the prerequisite technical expertise may serve as a constraint in this regard.

Further, in assessing the likeliness to recommend their colleagues to use the VCLS as an academic support tool as summarized in Figure $8(\mathrm{C})$, it is clear that once again a significant proportion $(79 \%)$ is likely in recommending their colleagues to use the VCLS as an academic support tool, while only much lesser proportions of learners indicated that they were not sure $(11 \%)$ or they will not recommend using the VCLS $(7 \%)$. Further analysis indicated that out of the learners who indicated that the VCLS was neither interesting nor helpful for the course, $75 \%$ were not familiar with the resource according to the feedback provided by the same learners on the familiarity of the VCLS. This suggests that the overall opinion of the learners on the VCLS is biased by the lack of familiarity with the resource and this could be significantly improved by facilitating further use of the VCLS by direct motivation such as making the use of the VCLS compulsory or by indirect means where the learners are encouraged to use the same by providing some academic reward in return.

\section{Summary, conclusions and future direction}

In this study, a "virtual chemistry lab space" (VCLS) was created using OER in order to facilitate learning during the pandemic lockdown, and it was administered among learners enrolled in an introductory undergraduate practical chemistry course (CYU3302 - Basic Practical Chemistry) at the Open University of Sri Lanka via the university LMS. Following the implementation, feedback was collected from the learners enrolled in the course regarding the use, effectivity, perception and any issues in using the resource.

As per the feedback collected regarding the VCLS from the learners from all demographic backgrounds, $76 \%$ of respondents indicated familiarity with the VCLS, while $59 \%$ indicated that they were interested in engaging in activities provided through this resource during the pandemic lockdown. A significant majority $(70 \%)$ indicated that the VCLS was helpful to understand the course content during the pandemic period, while $82 \%$ indicated that they are likely to use it in the future. The prevalent problems related to using the VCLS as part of the course delivery were lack of Internet access (31\%), lack of physical interactions (25\%) and lack of time $(23 \%)$, which need to be carefully taken into consideration if further use of the resource is advocated. However, the overall opinion on the VCLS (74\%) and the opinion on replacing part of the laboratory work associated with this course by the VCLS in future (48\%) was notably positive.

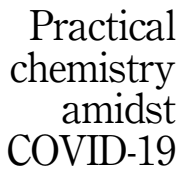


AAOUJ 16,3

Further analysis suggests that the overall opinion of the learners on the VCLS is biased by the lack of familiarity with the resource, which could be significantly improved by facilitating further use of the VCLS via direct or indirect motivation. Overall, it is notable that a majority of learners indicated that flexibility to the learners, access to learning resources and use of technology in education, all of which are important determinants in effective dissemination of knowledge, specifically in ODL, will improve due to the use of this novel tool, thus awarding notable credibility to the work discussed herein.

However, with the current state of the COVID-19 pandemic, the possibility of using the VCLS not as a supplementary tool, but for direct knowledge dissemination needs to be explored. Nevertheless, although the VCLS at its current state indicates drawbacks that may hinder its applicability as an effective content delivery tool, with the successful implementation and the overall positive response received from learners at the Open University of Sri Lanka, it is likely that the system could be developed further according to the findings of this study, such that the VCLS could be adopted across all other levels of practical chemistry. Hence, the VCLS indicates promising potential as an effective online knowledge dissemination tool to be used during the continuing social-distancing practices, or perhaps maybe even beyond, as a general practice adoptable in open and distance education.

\section{References}

Al-Fahad, F.N. (2009), "The learners' satisfaction toward online e-learning implemented in the College of Applied Studies and Community Service, King Saud University, Saudi Arabia: can e-learning replace the conventional system of education?", Proceedings of the IADIS International Conference E-Learning 2009, Part of the IADIS Multi Conference on Computer Science and Information Systems, 2009, Vol. 1 No. 2, pp. 238-246, MCCSIS.

Ali, W. (2020), "Online and remote learning in higher education institutes: a necessity in light of COVID-19 pandemic", Higher Education Studies, ERIC, Vol. 10 No. 3, pp. 16-25.

Basilaia, G., Dgebuadze, M., Kantaria, M. and Chokhonelidze, G. (2020), "Replacing the classic learning form at universities as an immediate response to the COVID-19 virus infection in Georgia", International Journal for Research in Applied Science and Engineering Technology, Vol. 8 No. 3, pp. 101-108.

Bates, A.W. and Bates, T. (2005), Technology, E-Learning and Distance Education, Psychology Press, Oxfordshire.

Boschmann, E. (2003), "Teaching chemistry via distance education", Journal of Chemical Education, ACS Publications, Vol. 80 No. 6, p. 704.

Brown, B.W. and Liedholm, C.E. (2002), "Can web courses replace the classroom in principles of microeconomics?”, American Economic Review, Vol. 92 No. 2, pp. 444-448.

Campbell, C.D., Challen, B., Turner, K.L. and Stewart, M.I. (2020), “\# DryLabs20: a new global collaborative network to consider and address the challenges of laboratory teaching with the challenges of COVID-19", Journal of Chemical Education, ACS Publications, Vol. 97 No. 9, pp. 3023-3027.

Carswell, L., Thomas, P., Petre, M., Price, B. and Richards, M. (2000), "Distance education via the Internet: the student experience", British Journal of Educational Technology, John Wiley \& Sons, Vol. 31 No. 1, pp. 29-46.

Casey, D.M. (2008), "The historical development of distance education through technology", TechTrends, Springer, Vol. 52 No. 2, pp. 45-51.

Chen, B. (2009), "Barriers to adoption of technology mediated distance education in higher-education institutions", Quarterly Review of Distance Education, Vol. 10 No. 4, pp. 333-338.

Chick, R.C., Clifton, G.T., Peace, K.M., Propper, B.W., Hale, D.F., Alseidi, A.A. and Vreeland, T.J. (2020), "Using technology to maintain the education of residents during the COVID-19 pandemic", Journal of Surgical Education, Elsevier, Vol. 77 No. 4, pp. 729-732. 
Christensen, R. (2002), "Effects of technology integration education on the attitudes of teachers and students", Journal of Research on Technology in Education, Taylor \& Francis, Vol. 34 No. 4, pp. 411-433.

Clark, R.E. (2000), "Evaluating distance education: strategies and cautions", International Journal of Educational Policy, Research, and Practice: Reconceptualizing Childhood Studies, Vol. 1 No. 1, pp. 3-16.

Code, J., Ralph, R. and Forde, K. (2020), "Pandemic designs for the future: perspectives of technology education teachers during COVID-19", Information and Learning Sciences, Emerald Publishing, Vol. 121 Nos 5/6, pp. 419-431.

Dalgarno, B., Bishop, A.G., Adlong, W. and Bedgood, D.R. Jr (2009), "Effectiveness of a virtual laboratory as a preparatory resource for distance education chemistry students", Computers and Education, Elsevier, Vol. 53 No. 3, pp. 853-865.

Dalgarno, B., Bishop, A.G. and Bedgood, D.R. Jr (2012), "The potential of virtual laboratories for distance education science teaching: reflections from the development and evaluation of a virtual chemistry laboratory", Proceedings of The Australian Conference on Science and Mathematics Education (Formerly UniServe Science Conference), Vol. 9.

Daniel, J. (2020), "Education and the COVID-19 pandemic", Prospects, Springer, Vol. 49 No. 1, pp. 91-96.

Devisakti, A. (2016), "Institutional factors that motivates adult learners in ODL", ASEAN Journal of Open and Distance Learning, Vol. 8 No. 2, pp. 67-76.

Dzakiria, H. (2012), "Illuminating the importance of learning interaction to open distance learning (ODL) success: a qualitative perspectives of adult learners in Perlis, Malaysia", European Journal of Open, Distance and E-Learning, ERIC.

Eddy, J.P. and Spaulding, D. (1996), "Internet, computers, distance education and people failure: research on technology", Education, Vol. 116, p. 391+.

Ferdig, R.E., Baumgartner, E., Hartshorne, R., Kaplan-Rakowski, R. and Mouza, C. (2020), Teaching, Technology, and Teacher Education during the COVID-19 Pandemic: Stories from the Field, Association for the Advancement of Computing in Education, Waynesville, NC.

Fergus, S., Botha, M. and Scott, M. (2020), "Insights gained during COVID-19: refocusing laboratory assessments online”, Journal of Chemical Education, ACS Publications, Vol. 97 No. 9, pp. 3106-3109.

Galusha, J.M. (1998), Barriers to Learning in Distance Education, ERIC.

Georgiou, J., Dimitropoulos, K. and Manitsaris, A. (2007), "A virtual reality laboratory for distance education in chemistry", International Journal of Social Sciences, Vol. 2 No. 1, pp. 34-41.

Goh, P.S. and Sandars, J. (2020), "A vision of the use of technology in medical education after the COVID-19 pandemic", MedEdPublish, Vol. 9, pp. 1-8.

Guohong, G., Ning, L., Wenxian, X. and Wenlong, W. (2012), "The study on the development of internet-based distance education and problems", Energy Procedia, Vol. 17, pp. 1362-1368.

Huang, J. (2020), "Successes and challenges: online teaching and learning of chemistry in higher education in China in the time of COVID-19", Journal of Chemical Education, ACS Publications, Vol. 97 No. 9, pp. 2810-2814.

Moore, M.G. (2013), Handbook of Distance Education, Routledge, Oxfordshire.

Ng, K.C. (2007), "Replacing face-to-face tutorials by synchronous online technologies: challenges and pedagogical implications", International Review of Research in Open and Distributed Learning, Athabasca University Press (AU Press), Vol. 8 No. 1, pp. 1-15.

Qiang, Z., Obando, A.G., Chen, Y. and Ye, C. (2020), "Revisiting distance learning resources for undergraduate research and lab activities during COVID-19 pandemic", Journal of Chemical Education, ACS Publications, Vol. 97 No. 9, pp. 3446-3449. 
AAOUJ 16,3

Rodríguez-Rodríguez, E., Sánchez-Paniagua, M., Sanz-Landaluze, J. and Moreno-Guzmán, M. (2020), "Analytical chemistry teaching adaptation in the COVID-19 period: experiences and students' opinion”, Journal of Chemical Education, ACS Publications, Vol. 97 No. 9, pp. 2556-2564.

Soares, R., De Mello, M.C.S., Da Silva, C.M., Machado, W. and Arbilla, G. (2020), "Online Chemistry education challenges for Rio de Janeiro students during the covid-19 pandemic", Journal of Chemical Education, ACS Publications, Vol. 97 No. 9, pp. 3396-3399.

Tabata, L.N. and Johnsrud, L.K. (2008), "The Impact of faculty attitudes toward technology, distance education, and innovation", Research in Higher Education, Vol. 49 No. 7, p. 625.

Tait, A. (2002), "Rethinking learner support in the Open University UK: a case study", Rethinking Learner Support in Distance Education: Change and Continuity in an International Context, pp. 185-197.

Tigaa, R.A. and Sonawane, S.L. (2020), "An international perspective: teaching chemistry and engaging students during the COVID-19 pandemic", Journal of Chemical Education, ACS Publications, Vol. 97 No. 9, pp. 3318-3321.

Tran, K., Beshir, A. and Vaze, A. (2020), "A tale of two lab courses: an account and reflection on the teaching challenges experienced by organic and analytical chemistry laboratories during the COVID-19 period", Journal of Chemical Education, ACS Publications, Vol. 97 No. 9, pp. 3079-3084.

Valle-Suárez, R.M., Calderón-Mendoza, G.L., Lanza-Sorto, N.A. and Ponce-Rodríguez, H.D. (2020), "Teaching instrumental analytical chemistry in the framework of COVID-19: experiences and outlook”, Journal of Chemical Education, ACS Publications, Vol. 97 No. 9, pp. 2723-2726.

Willis, B.D. (1993), Distance Education: A Practical Guide, Educational Technology, Englewood Cliffs, NJ.

\section{Corresponding author}

Lahiru A. Wijenayaka can be contacted at: lawij@ou.ac.lk

For instructions on how to order reprints of this article, please visit our website:

www.emeraldgrouppublishing.com/licensing/reprints.htm

Or contact us for further details: permissions@emeraldinsight.com 